\title{
XXIII. Remarks on the weather during the quarter ending December 31, 1848
}

\section{James Glaisher Esq.}

To cite this article: James Glaisher Esq. (1849) XXIII. Remarks on the weather during the quarter ending December 31, 1848, Philosophical Magazine Series 3, 34:228, 182-193, DOI: $10.1080 / 14786444908646205$

To link to this article: http://dx.doi.org/10.1080/14786444908646205

册 Published online: 30 Apr 2009.

Submit your article to this journal $₫$

Џ Article views: 2

Q View related articles $₫$ 
The calculation by means of equations (14.) and (15.) does not require a table of natural tangents. It requires the logarithmic tables to be opened six times.

6 . For the use of persons who may wish to make the calculations without being able to follow the steps of this investigation, it may be desirable to give the result separately; it is this.

Let $\zeta$ be the zenith distance of the shooting star at the moment of disappearance, $Z$ the zenith distance of the point of the heavens diametrically opposite the sun, and $\phi$ the distance of this point from the shooting star. Find an angle $\psi$ such that

$$
\operatorname{cotan} \psi=\cos \zeta \sec \mathrm{Z} \operatorname{cosec} \varphi-\operatorname{cotan} \varphi .
$$

Then the distance $\rho$ of the shooting star from the spectator in terms of the earth's semidiameter as the unit is

$$
\rho=\cos Z \operatorname{cosec} \phi \tan \frac{1}{2} \psi \text {. }
$$

3 Stone Buildings, Lincoln's-Inn, February 14, 1849 .

XXIII. Remarks on the Weather during the Quarter ending December 31, 1848. By James Glaisher, Esq., of the Royal Obserzatory, Greenwich*.

THE meteorological returns for the past quarter furnished 1 to the Registrar-General have been received from stations spread over the country. The observations have been made, for the most part by experienced observers, upon an uniform plan. The following remarks are based upon observations which have been furnished either to myself or to the Registrar-General, and drawn up to accompany the meteorological tables published by the Registrar-General, all of which have been examined by myself, and reduced under my direction.

The weather during the period has been variable. The changes of temperature have ben frequent and great, there has been an nnusually large number of exhibitions of the aurora borealis, and the magnetic instruments have been greatly disturbed. The amount of electricity in the atmosphere has been smail, many days together having passed without the instruments at Greenwich being affected.

From the 1st of October to the 10th the excess of temperature above the average of seven years was $6^{\circ} \cdot 6$; the greatest daily excess was $12^{\circ} \cdot 3$ on the 7 th. Between the 11 th and

* Communicated by the Author. 
21 st the temperature was $4^{\circ} \cdot 5$ below the average; on the 18 th it was $10^{\circ}$ in defect. From October 22 to October 30 it was $5^{\circ} \cdot 3$ in excess; the greatest was $7^{\circ \cdot 7}$ on the 27 th. From October 31 to November 16 the temperature was mostly below the average, its mean defect was $4^{\circ} \cdot 2$, its greatest within the period was $10^{\circ} .2$ on the 4 th. From November 17 to December 19 the temperature exceeded the average by $4^{\circ} \cdot 8$. On December 7 the excess was $12^{\circ} \cdot 4$; on the 8 th was $15^{\circ} .7$; on the 9 th was $14^{\circ} \cdot 4$; and on the 10 th was $10^{\circ} \cdot 1$. From December 20 to December 24 the defect was $6^{\circ} \cdot 2$; from December 25 to December 29 the excess was $5^{\circ} \cdot 8$; and it was $2^{\circ} \cdot 3$ below the average on December 30 and 31 . The following are the particulars of each subject of investigation arranged as in the preceding quarters.

The mean temperature of the air at Greenwic $\tilde{h}$ -

For the month of October was $51^{\circ} \cdot 6$, which is $2^{\circ} \cdot 5,6^{\circ} \cdot 2$, $3^{\circ} \cdot 6,2^{\circ} \cdot 1,1^{\circ} \cdot 4$, and $1^{\circ} \cdot 1$ above those of the years 184.1 to 184.6 respectively, and $1^{\circ} .3$ belore that in the year 1847 ; or it is $2^{\circ} .3$ above the average of these seven years;

For the month of November was $43^{\circ} \cdot 8$, which is $1^{\circ} \cdot 1$ and $1^{\circ} .0$ above those of the years 1841 and 1842 , of the same value as that of $1843,0^{\circ} \cdot 2,2^{\circ} \cdot 0,2^{\circ} \cdot 2$, and $3^{\circ} \cdot 1$ below those of the years 184.4 to 184.7 respectively; or it is $0^{\circ} \cdot 7$ below the average of these seven years;

For the month of December was $44^{\circ} \cdot 0$, which is $3^{\circ} \cdot 5,0^{\circ} \cdot 1$, $11^{\circ} \cdot 0,2^{\circ} \cdot 3,11^{\circ} \cdot 1$ and $1^{\circ} \cdot 2$ above those of the years $1841,184 \%$, $1844,1845,1846$, and 184.7 respectively; and $1^{\circ} .0$ below that of the year 184,2 , or it is $4^{\circ} \cdot 1$ above the average of these seven years.

The mean value for the quarter was $46^{\circ} .5$; that for 1841 was $44^{\circ} \cdot 0$; for 181.2 was $44^{\circ} \cdot 4$; for 1843 was $45^{\circ} \cdot 2$; for 1844 was $42^{\circ} \cdot 2$; for 1845 was $45^{\circ} \cdot 9$; for 1846 was $43^{\circ} \cdot 1$; and for 184.7 was $4.7^{\circ} .5$; so that the excess of temperature this quarter above the corresponding quarter in the years 1841 to 1846 was $2^{\circ} \cdot 5,2^{\circ} \cdot 1,1^{\circ} \cdot 3,4^{\circ} \cdot 3,0^{\circ} \cdot 6$, and $3^{\circ} \cdot 4$ respectively; the only year between 1841 and 1847 whose mean temperature for this period was greater than that for the present year was 184.7, and the difference is $1^{\circ} \cdot 0$. The average value for this quarter from the seven preceding years was $44^{\circ} \cdot 6$; so that the mean temperature of the air for the quarter ending December 31, 1848 , was above that of the corresponding quarter in the preceding seven years by $1^{\circ} \cdot 9$.

The mean temperature of evaporation at Greenwich-

For the month of October was $49^{\circ} \cdot 3$, which is $1^{\circ} .5$ above that for the preceding seven years;

For the month of November was $41^{\circ} \cdot 7$, which is $1^{\circ} \cdot 7$ below that for the preceding seven years; 
For the month of December was $42^{\circ} .3$, which is $3^{\circ} \cdot 5$ above that for the preceding seven years.

The mean value for the quarter was $44^{\circ} \cdot 4$, which is $1^{\circ} \cdot 1$ above that for the preceding seven years.

The mean temperature of the dcro-point at Greenwich-

For the month of October was $47^{\circ} \cdot 4$, which is $2^{\circ} \cdot 3,5^{\circ} \cdot \mathrm{C}$, $2^{\circ} \cdot 7,1^{\circ} \cdot 4,0^{\circ} \cdot 9$, and $0^{\circ} \cdot 2$ above those of the years 1841 to 1846 respectively, and $1^{\circ} .7$ below that of the year 1847 ; or it is $1^{\circ} \cdot 6$ above the average of these seven years;

For the month of November was $38^{\circ} \cdot 8$, which is $1^{\circ} \cdot 0,1^{\circ} \cdot 6$, $2^{\circ} \cdot 1,3^{\circ} \cdot 1,4^{\circ} \cdot 0,4^{\circ} \cdot 3$, and $5^{\circ} \cdot 3$ below those of the y'ears 1841 to 1847 ; or it is $3^{\circ} .0$ belore the average for these seven years;

For the month of December was $40^{\circ} \cdot 1$, which is $4^{\circ} \cdot 9,10^{\circ} \cdot 1$, $2^{\circ} \cdot 4,10^{\circ} \cdot 7$, and $0^{\circ} \cdot 3$ above those of the years $1841,184.4$, 1845,1846 , and 184.7 respectively, $3^{\circ} \cdot 1$ and $1^{\circ} \cdot 9$ below those of the years 184.2 and 1843 ; or it is $3^{\circ} .3$ above the average of these seven years.

The mean value for the quarter was $42^{\circ} \cdot 1$, which is $0^{\circ} \cdot 7$ above the average for the corresponding period of the preceding seven years.

The mean roeight of water in a cubic foot of air for the quarter was 3.3 grains, which is 0.1 grain greater than the average of the preceding seven years.

The additional reight of roter required to saturate a cubic foot of air was $0 \cdot 54$ grain. This value from the preceding seven years was 0.38 grain.

The mean degree of humidity of the atmosphere for October was 0.853 , for November was 0.84 .8 , and for December was 0.873 . The averages for the seven preceding years were 0.888 , 0.909 , and 0.900 respectively. The value for the quarter was 0.858 , which is 0.041 less than the average for these years.

The mean elastic force of vapour for the quarter was 0.285 inch, which is 0.008 less than the average for the preceding seven years.

The mean reading of the barometer at Greenwich for October was $29 \cdot 646$ inches, for November was $29 \cdot 785$ inches, and for December was 29.807 inches; these values are 0.014 inch below, 0.075 inch above, and 0.028 inch below the average for the same months from the preceding seven years. The mean value for the quarter was $29 \cdot 74.6$ inches, which is 0.011 above the average for these years.

The average weight of a cubic foot of air under the average temperature, humidity, and pressure, was 540.3 grains; the average for the seven preceding years was 542 grains.

The rainfallen at Greenwich in October was 3.50 inches; in November was 1.20 inch; and in December was 2.55 inches. In October, in the years 1841 to 1847 , were $5.95,1.41,4.25$, 
$4.03,1.38,5.13$, and 2.00 inches respectively; the mean of these values is 3.4 .5 inches. In November, in the years 1841 to 1847 , were $3.70,4 \cdot 28,2 \cdot 30,4 \cdot 32,2 \cdot 40,1 \cdot 52$, and $2 \cdot 00$ inches respectively; the mean of these values is 2.92 inches. In December, in the years 1841 to 1847 , were $2.40,0.74,0.40$, $0 \cdot 4.2,2 \cdot 00,1 \cdot 13$, and $2 \cdot 00$ respectively; and the mean of these values is 1.29 inches. The depth of rain in October this year was nearly the same as the average from the seven preceding yenrs, the fall in three instances being less, and in four exceeding that of this year. In November the fall in this year was less than that in any corresponding period since the year 1828 , its amount being 1.72 inch less than the average from the seven preceding years. In December the fall exceeded that in every December since 1833, the mean excess being 1.26 inch above the average since 1841. In October rain fell on twenty-four days, on fourteen of which the amount was less than $0 \cdot 1$ inch; on six it was between 0.1 inch and 0.2 inch; on three it was greater than 0.2 inch and less than 0.3 inch; there was one instance exceeding $0.3 \mathrm{inch}$, one exceeding $0.4 \mathrm{inch}$, and one between 0.5 inch and 0.6 inch. In November there were only two instances of the fall in one day exceeding 0.1 inch; on one of these it amounted to 0.390 inch. In December there were three instances exceeding 0.1 inch, five exceeding 0.2 inch, and one amounting to 0.685 inch; on all other days the fall was less than 0.1 inch. The amount for the quarter is 7.25 inches, and the average from the seven preceding years is 7.66 inches.

The fall of rain during the year 1848 at Greenwich was 31.9 inches; in 1841 it was 33.3 inches; in 1842 it was 22.6 inches; in 1843 it was 24.5 inches; in 1844 it was 25 inches; in 1845 it was 22.3 inches ; in 1846 it was 25.3 inches; and in 184.7 it was 17.6 inclues. The mean of their values is 24.4 inches; so that the excess of the fall of rain this year over the average from the seven preceding years is 7.5 inches. At Beckington it was 43.16 inches; in 184.5 it was 24.94 inches; in 1846 it was 32.30 inches; and in 1847 it was 28.74 inches. In 1845 it fell on 134 days; in 1846 on 168 days; in 1847 on 151 days; and in 1848 on 219 days, as registered by the Rev. Charles Blathwayt.

At St. John's Wood, London, the fall exceeded the average from ten years by $5 \cdot 05$ inches, as observed by George Leech, Esq.

At Aylesbury it fell on 174 days, amounting to 34.68 inches, exceeding the average from the preceding six years by 9.5 inches, as observed by Thomas Dell, Esq.

At Empingham it amounted to $30 \cdot 36$ inches, which is the 
largest fall since 1830, as observed by William Fancourt, Esq.

At Derby was 40.07 inches, exceeding the average from the preceding four years by more than 10 inches, and by 12 inches the average from twenty years, as observed by John Davis, Esq.

At Leeds was 37.86 inches, it having fallen on 244 days. In the year 1846 it fell on 218 days, and in 184.7 it fell on 174 days; and the amount was $28 \cdot 442$ inches, as observed by Charles Charnock, Esq.

At Hereford was $46 \cdot 41$ inches; the average fall from a long series of years is rather more than 30 inches, as observed by James Pendergrass, Esq.

The fall of rain during the year 1848 all over the country was about one-third larger than the average fall, and this excess fell during the first three quarters. The fall in the last quarter was about its average value at most places.

The temperature of the water of the Thames was $47^{\circ} \cdot 5$ by day, and $45^{\circ} .7$ by night. The water, on an average, was of the same temperature as that of the air. During the quarter the temperature of the water has changed more than usual; the decrease of temperature from November 4 was rapid.

The direction of the wind at Greenwich-

From October 1 to 11 was chiefly S.W.; between October 11 and 20 was chiefly N.; and from October 20 to 31 was mostly S.;

From November 1 to 7 was variable, but was chiefly S.W. and $N$.W.; from the 7 th to 15 th was $N$.; from the 16 th to the 21 st was S.W.; from the 21 st to the $23 \mathrm{rd}$ was S.E. ; and was chiefly S.W. to the end of the month;

From December 1 to 9 was S.W.; from the 9 th to the 15 th was mostly S. by E., and was then N. and N.E. to the end of the month.

The daily horizontal movement of the air-

From October 1 to 11 was about 160 miles; the greatest value during the period was 300 miles, and the least was 80 miles; from October 11 to the 20 th was 130 miles; the greatest was 270 miles, and the least was 30 miles; and from October 20 to the end of the month was 150 miles; the greatest being 240 miles, and the least 40 miles. The average for the month was 150 miles daily;

From November 1 to 7 was 150 miles, the greatest and least being 245 miles and 10 miles; from November 7 to 15 was 110, the extremes being 200 miles and 80 miles; from the $16 \mathrm{~h}$ to the $21 \mathrm{st}$ was 250 miles, the extremes being 4.95 miles and 185 miles; from the 21 st to the $23 \mathrm{rd}$ was 190 miles; and 
from the 24th to the end of the month was 230 miles, the extremes being 300 miles and 70 miles; the average for the month was 165 miles;

From December 1 to 9 was 290 miles daily; from the 9th to the 15 th was 170 miles; and it was 94 miles from the 15 th to the end of the quarter. The extremes in December were 320 miles and 10 miles. The average for the month was 170 miles, and that for the quarter was 160 miles daily.

In October the readings of the thermometer on grass were at and below $32^{\circ}$ on four nights ; between $32^{\circ}$ and $40^{\circ}$ on fourteen and above $40^{\circ}$ on thirteen rights. In November the lowest reading was $21^{\circ} .5$; the readings were below $32^{\circ}$ on eighteen nights, and above $32^{\circ}$ on thirteen nights. In December the lowest reading was $18^{\circ}$, and the readings were below $32^{\circ}$ on twelve nights, between $32^{\circ}$ and $40^{\circ}$ on fifteen nights, and above $40^{\circ}$ on four nights.

The mean amount of clouds was 7.3 in October, and 6.7 both in November and December. The averages for the seven preceding years were $6 \cdot 9,7 \cdot 2$, and $7 \cdot 2$ respectively.

There were no less than twenty-four exhibitions of the aurora borcalis during the quarter ending December 31, 184.8, which occurred on October 18, 19, 20, 22, 24, 25, 27 and 30 , both in the morning and in the evening of the 30th; November 13,14, 17, 18, 21, 23, 24, 25, 26, 30; December 13, 17, 22,27 and 29. At all these times the magnets were more or less disturbed. In the weekly reports it was stated that from October 17 to 30 the magnetic instruments were almost always under some cause of disturbance, and particularly on the 17 th, $18 \mathrm{th}, 19 \mathrm{th}, 23 \mathrm{rd}$ and $24 \mathrm{th}$, slightly on the 21 st and $22 \mathrm{nd}$, and moderate on the remaining days. The finest aurora was that on the 17th of November; this was best observed by Professor Challis, and described by him in the Cambridge Chronicle. The most important part of his communication was that relative to the varying position of the corona. Professor Challis says, "I took twenty-four observations of the position of the corona, partly. by reference to stars, and partly by a small altitude and azimuth instrument expressly constructed for this kind of observation, which I call a meteoroscope. A comparison of the results of the several observations seemed to show that the central point has not a fixed altitude and azimuth, but oscillates in a capricious manner about a medium position, more especially in the azimuthal direction." Observations of this kind are of the highest importance for comparison with the varying positions of the corona with the simultaneous variations of the magnetic dip and positions of the magnets. 
Thunder-storms occurred at Whitehaven on October 9, 23, 28, 29, November 22, December 1; at Preston on Dec. 1; at Stonyhurst on December 9, distant thunder and lightning were noticed. Thunder was heard at Exeter on October 22 and on December 1. Lightning was seen at Truro on October 16, at Stone on October 28, at Saffron Walden on December $I$ and 6 , at Durham on October 18 and 28, at Whitehaven on December 2, at Greenwich on October 25, and at Stone on October 6 and November 3.

Hail fell at Truro on October 18, November 4, 7 and 8, at Greenwich on December 1, at Exeter on December 23, at Whitehaven on October 23, 28, 29, December 1 and 4 .

Snow fell at Exeter, Empingham, and Saffron Walden on October 18, at Truro, Southampton, Greenwich, and Empingham on November 4, at Truro on November 7 and 8 , at Hartwell on November 23 and December 2, and at Exeter on December 23.

Solar halos were seen at Maidenstone Hill, Greenwich, on October 5, 24, 29, and November 25; at Stone on Nov. 30; at Greenwich on October 24; at Highfield House on Oct. 1, 4, 18, 29, and December 2.

On November 8 a mock sun was seen at Highfield Honse.

Lunar halos were seen on October 8, December 2, 4, 10 and 12.

Large and continuous falls of rain.-On October 23, at Latimer Rectory, rain to the depth of 1.7 inch fell in twentyfour hours following 9 A.M.

At Falmouth, on December 27, there was a heavy fall of rain; in a few hours 1.5 inch fell. At Truro, on December 27, rain fell to the depth of $2 \cdot 1$ inches. In some parts of the county of Cornwall the fall of rain on December 27 exceeded 2 inches; at Penzance more than 2 inches fell, Great damage was done by the consequent floods.

The mean monthly values of the several subjects of research for the times of observations are appended to the report of the Registrar-General.

The monthly mean temperatures in the counties of Cornwall and Devonshire exceeded those at other places; but there seems to have been a good deal of bad weather in these counties, and more snow, hail and sleet seems to have fallen in these counties than elsewhere.

The readings of the barometer till October 4 were between 29.5 inches and 29.7 inches; after October 4 it steadily increased, and passed the point 30 before noon on the 5 th, and remained above this point until the 7 th ; the highest reading was $30^{\circ} 062$, and took place at $9^{\mathrm{h}}$ A.M. on the 6 th. Between 
the 8 th and the 20 th the fluctuations were very frequent, with generally larger decreasing than increasing readings. On the 25th the reacting was $29 \cdot 111$, and was the lowest in the month. On the 26th, at $6^{\mathrm{h}}$ P.M., it had increased to $29 \cdot 749$, and after this the readings were low, and with slight variation to the end of the month. The extreme difference of the readings during the month was 0.953 inch.

From November 1 to 6 the readings were between $29 \cdot 6$ and 29.4 ; it then increased from the latter reading to 30.248 on the 10 th at midnight. On the 15 th the reading was 30.348 , which was the highest during the month. On the 18th, at midnight, the reading was $29^{\circ} 417$; on the 19 th the increase was $0.520 \mathrm{inch}$, and on the 20 th the decrease was 0.454 . On the $23 \mathrm{rd}$, at midnight, the reading was $29 \cdot 048$, which was the lowest in the month. On the 25 th, at noon, the reading was 29.984; after this the changes were small till the end of the month. 'The range during the month was 1.300 inch.

On December 1 the reading decreased 0.436 , and was 29.284 at midnight; on the 2 nd it increased 0.253 , and on the $3 \mathrm{rd}$, at $10^{\mathrm{h}}$ A.M., it was 29.730 ; it then decreased rapidly, and the lowest reading during the quarter took place on the 5 th at $6^{\mathrm{h}}$ A.M.; it increased slowly till the 7 th, and then quickly from the 7 th to the 10 th. The reading was above 30 from the 10 th to the 13th; it was between 29.5 and 30 from the 13 th to the 18 th. On this day, at $6^{\text {h }}$ P.M., it was 29.677 , and on the $22 n d$, at midnight, the reading was 30.266 , the highest during the month. The reading was generally high till the end of the month. The range during the month was 1.432 inches.

At Stonyhurst, from Nov. 1 to 6 , the readings were between 29.098 and 29.355 , it then increased to 30.150 at 11 P.M. ; on the 12 th it remained above 29.8 till November 17 , when it decreased suddenly to 29.518 , and gradually to 28.923 on the 20 th ; it increased to $29 \cdot 110$ on November 21 , but decreased to $2 S \cdot 624$ by $3^{\text {h }} \mathbf{P}, M$. on the $22 \mathrm{nd}$; it then increased stearlily till November 25 at 9 A.M., when it was 29.615 , and the variations afterwards were small.

On December 5, at $9^{\mathrm{h}}$ A.M., the reading was 28.421 , the wind at the time blowing strongly from the west.

Charles Charnock, Esq., of Stourton Lodge, Leeds, has kindly furnished me with the following agricultural report for the North Riding of Yorkshire.

"The continued rain from the 20th of September to November 1 prevented any large quantity of wheat being sown, even on dry lands; and that which was sown was finished in a very unsatisfactory manner. The comparative dry weather 
from November 1 to 12 enabled the farmers to sow a great portion of their wheat. On strong wheat soils a large breadth remains for spring sowing with wheat or oats. The seed time upon an average was nearly a month later than usual, and the seed since has vegetated very slowly, owing to the wetness and coldness of the soil.

"The continued fall of rain in September completely destroyed the crops of corn in the backward situations, and large quantities of barley, oats and beans, in the straw have been carried into the yards for the cattle and pigs, as not worth the expense of thrashing.

"The disease among potatoes has not been found so destructive as was anticipated, and will be more injurious to the grower than to the consumer. In some situations the crops were totally, and in others partially destroyed; yet from the great extra breadth planted with this vegetable last spring, there will perhaps be no great scarcity felt. I was most surprised by seeing field potatoes taken up as late as the 18 th of December.

"The crops of corn now thrashing are very deficient both in quantity and quality. Turnips are an indifferent crop, and do not bear much eating; the sheep folded upon them have been prevented from doing well by the wetness of the weather. Symptoms of rot are apparent among many flocks of sheep.

"From the open weather the grass land has been full of meat, and has kept cattle out of the straw yards longer than usual. The disease on the lungs of beasts and milch-cows has been prevalent and exceedingly fatal; the mortality is calculated to have been 95 per cent. of those attacked.

"Within the last few weeks the epidemic prevalent in the years 1839 and 1840 has appeared among lean stock; its symptoms are blisters on the tongue and lameness. It is not often fatal, but reduces the cattle attacked by it very much.

"Employment for agricultural labourers is scarce, and its ill effects are much augmented by the great number of men who have been discharged from the railways, whose intemperate and vicious habits tend greatly to demoralise the agricultural districts.

"Many of the low grounds have been flooded, and farming operations prevented in consequence."

Themean of the numbers in the first column is 29.608 inches, and this value may be considered as that of the pressure of dry air for England during the quarter ending December 31, 1848. The differences between this number and the separate results contained in the first column show the probable sums of the errors of observation and reduction; the latter arising partly 
from erroneously assumed altitudes, and partly from the index error of the instruments not having been determined. In most cases the sums of their errors are small.

The mean of the numbers in the second column, for those places situated in Cornwall and Devonshire, is $4.7^{\circ} \cdot 9$; for those places situated south of latitude $52^{\circ}$, including Chichester and Hartwell, is $44^{\circ} \cdot 6$; for those places situated between the latitudes of $52^{\circ}$ and $53^{\circ}$, including Saffron Walden and Highfield House, is $44^{\circ} \cdot 2$; for those places situated between the latitudes of $53^{\circ}$ and $54^{\circ}$, including Liverpool and Whitehaven, is $43^{\circ} .3$; and for Durham and Newcastle is $43^{\circ} .0$. These values may be considered as those of the mean temperature of the air for their parallels of latitude during the quarter ending December 31, 1848.

The average daily range of the temperature of the air in Cornwall and Devonshire was $9^{\circ} \cdot 6$; at Liverpool and Whitehaven was $6^{\circ} \cdot 9$; south of latitude $52^{\circ}$ was $11^{\circ} \cdot 6$; between the latitude of $52^{\circ}$ and $54^{\circ}$ was $9^{\circ} 6$; and at Durham and Newcastle was $8^{\circ} \cdot 9$.

The greatest mean daily ranges of the temperature of the air took place at Greenwich, Hartwell, Latimer Rectory, and Aylesbury respectively; and the least occurred at Whitebaven, Guernsey, Torquay, Liverpool, and Truro respectively.

The highest thermometer readings during the quarter were $76^{\circ}$ at Hartwell and Leicester, $74^{\circ}$ at Greenwich and Aylesbury. The lowest thermometer reading was $20^{\circ} .5$ at Stonyhurst, and readings about $21^{\circ}$ occurred at several places. The extreme range of temperature of the air during the quarter was therefore about $55^{\circ}$.

The average quarterly range of the reading of the thermometers in air in Cornwall and Devonshire was $37^{\circ} .0$; at $\mathrm{Li}$ verpool and Whitehaven was $36^{\circ} .9$; and the mean of the numbers at all the remaining places is $48^{\circ} .7$.

The mean temperature of the dew-point in Cornwall and Devonshire was $43^{\circ} .5$; at all places south of $53^{\circ}$ was $41^{\circ} \cdot 6$; and it was $39^{\circ} \cdot 6$ at places north of $53^{\circ}$.

The great mass of air has passed from the south-west in all places except Exeter and Stonyhurst, at both of which places it seems to have passed from the north.

From the numbers in the tenth column the distribution of clouds has been the same at all places, and such as to have covered somewhat more than three-fifths of the whole sky.

Rain has fallen on the greatest number of days during the quarter at Highfield House, Stonyhurst, Derby, Leeds, Helston and Latimer, and the average number at those places was 63. It fell on the least number of days at Aylesbury, 


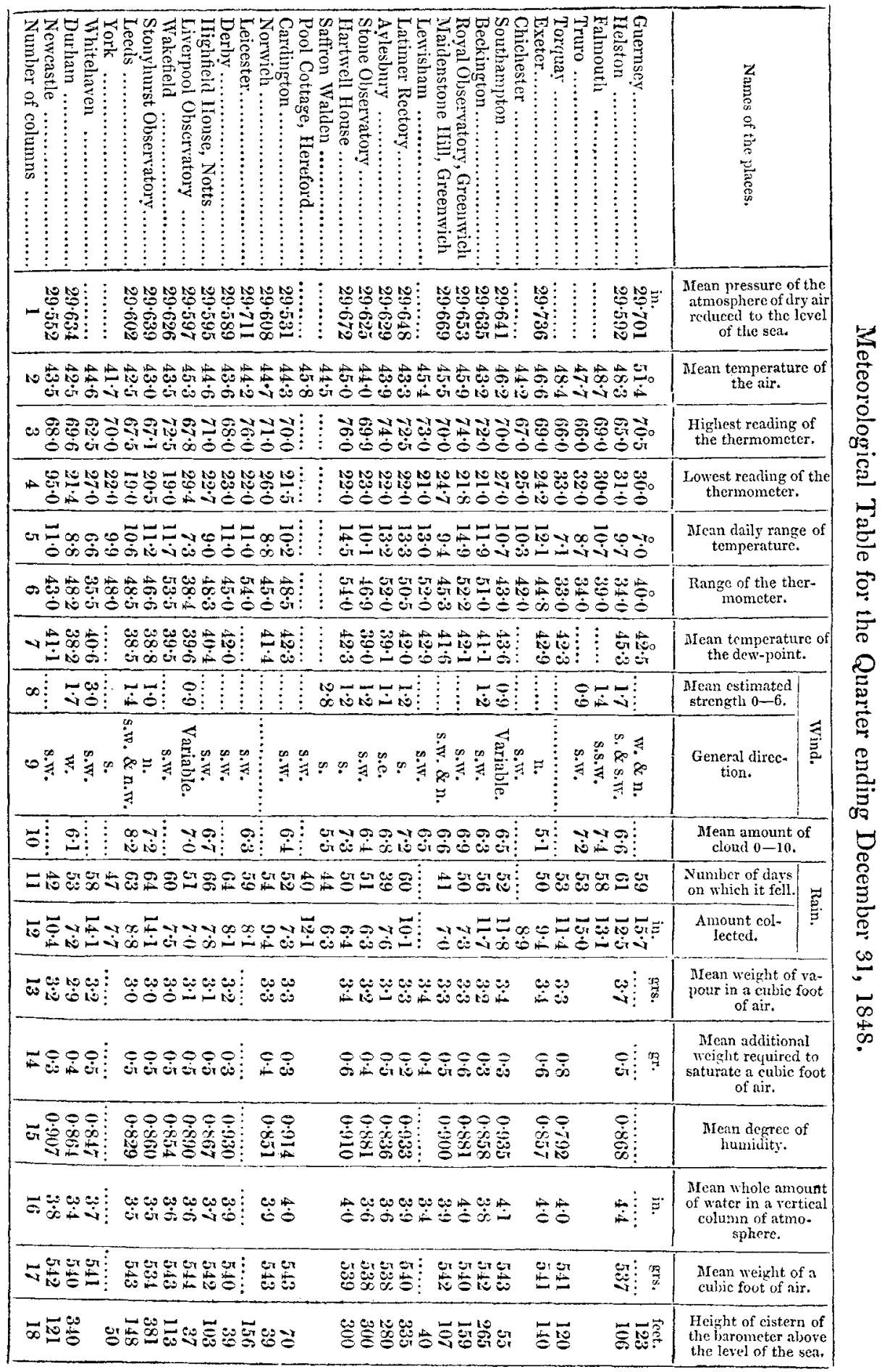


Hereford, Newcastle and Saffron Walden, and the average number at these places was 41 . The places at which the largest falls have taken place were Guernsey, Truro, Wakefield, Whitehaven, Falmonth and Helston. 'The falls were smallest in amount at Saffron Walden, Stone, Hartwell and Liverpool. The average fall in the counties of Cornwall and Devonshire was $12^{\circ} .3$; and at all other places except Southampton, Beckington, Hereford, Stonyhurst and York, was $8^{\circ} \cdot 5$.

The numbers in column 13 to 17 show the mean values of the hygrometrical results at every station; from which we find that-

The mean weight of vapour in a cubic foot of air for all places (excepting Cornwall and Devonshire) in the quarter ending December 31,1848 , was 3.2 grains.

The mean additional weight required to saturate a cubic foot of air in the quarter ending December 31,1818 , was 0.49 grain.

The mean degree of humidity (complete saturation =1) in the quarter ending December 31 , 1848, was 0.884 .

The mean amount of vapour mixed with the air would have produced water, if all had been precipitated at one time on the surface of the earth to the depth of 3.7 inches.

The mean weight of a cubic foot of air at the level of the sea, under the mean pressure, temperature and humidity, at the mean height of 160 feet, was 54.1 grains.

And these values for Cornwall and Devonshire were 3.5 grains; 0.6 grain $; 0.839 ; 4.1$ inches, and 540 grains respectively.

XXIV. On the Expression for the remaining roots of a complete Cubic, when one root is found. By J.R. Young, Professor of Mathematics, Belfast*.

THE following expression for two roots of an incomplete cubic equation, in terms of the third root, is given at page 216 of the Analyse Algébrique of Garnier, namely,

$$
-\frac{x_{1}}{2} \pm \sqrt{ }\left\{-3\left(\frac{x_{1}}{2}\right)^{2}-q\right\}
$$

where $q$ represents the coefficient of $x$, the term in $x^{2}$ being absent, and where $x_{1}$ is a root already found.

This formula I obtained independently, and gave it at page 322 of the second edition of my book on Equations. I

* Communicated by the Author.

Phil. Mag. S. 3. Vol, 34. No. 228, March 1849. 